\title{
Association between statin use and osteoporotic fracture in patients with chronic obstructive pulmonary disease: a population-based, matched case-control study
}

Hung-Yi Chen ${ }^{1,2+}$, Pei-Yu Su ${ }^{3}$, Tsung-Kun Lin ${ }^{4,5+}$ and Gwo-Ping Jong ${ }^{6^{*}}$ (i)

\begin{abstract}
Background: In the recent years, chronic obstructive pulmonary disease (COPD) has been found to be associated with a higher risk of new-onset osteoporotic fracture (NOF). However, the existence of such an association in the COPD patients receiving statin treatment remains unknown. The present study aimed to investigate the association between COPD and NOF in statin-treated patients.

Methods: The present study was conducted over a period of 10 years (January 2004 to December 2013) in Taiwan. COPD patients receiving statin treatment were included in the statin user group, whereas the randomly selected statin non-users, with 1:1 matching for sex, age, index date, and Charlson Comorbidity Index, were included in the statin non-user group. The hazard ratio (HR) of NOFs in COPD patients was estimated between statin user and nonuser groups.

Results: A total of 86,188 cases were identified as the statin-treated patients, and 86,188 subjects were included in the control group of statin non-users. Initially, the risk of NOF was found to be higher among the statin users as compared to non-users [HR, 1.12; 95\% confidence interval $(\mathrm{Cl}), 1.01-1.25]$. However, the calculation of risk for NOFs after the adjustment for age, sex, comorbidities, and concurrent medications indicated no association of NOF (HR, $0.81 ; 95 \% \mathrm{Cl}, 0.55-1.21)$ with COPD in patients receiving statin treatment as compared to statin non-users.
\end{abstract}

Conclusion: The results of the study provided first evidence for the absence of any association between COPD and NOFs in statin-treated patients during a follow-up period of 10 years. Thus, the findings of this study might support the hypothesis stating the potent pleiotropic effects of statins. In clinical practice, these drugs might prove beneficial for the patients with COPD.

Keywords: Chronic obstructive pulmonary disease, Osteoporosis fracture, Statin, Dyslipidemia, Case-control study, Cohort study, Taiwan

\footnotetext{
* Correspondence: cgp8009@yahoo.com.tw

${ }^{\dagger}$ Hung-Yi Chen and Tsung-Kun Lin share equal contribution.

${ }^{6}$ Department of Internal Medicine, Chung Shan Medical University Hospital and Chung Shan Medical University, Taichung, Taiwan, Republic of China Full list of author information is available at the end of the article
}

(c) The Author(s). 2020 Open Access This article is licensed under a Creative Commons Attribution 4.0 International License, which permits use, sharing, adaptation, distribution and reproduction in any medium or format, as long as you give appropriate credit to the original author(s) and the source, provide a link to the Creative Commons licence, and indicate if changes were made. The images or other third party material in this article are included in the article's Creative Commons licence, unless indicated otherwise in a credit line to the material. If material is not included in the article's Creative Commons licence and your intended use is not permitted by statutory regulation or exceeds the permitted use, you will need to obtain permission directly from the copyright holder. To view a copy of this licence, visit http://creativecommons.org/licenses/by/4.0/ The Creative Commons Public Domain Dedication waiver (http://creativecommons.org/publicdomain/zero/1.0/) applies to the data made available in this article, unless otherwise stated in a credit line to the data. 


\section{Background}

In the past few decades, chronic obstructive pulmonary disease (COPD) has emerged as the most common chronic respiratory disease worldwide [1]. It is a chronic lung disease, characterized by difficulty in breathing and obstructed air flow. According to the global estimates of 2016, COPD affected approximately 251 million adults and ranked third among the leading causes of death in adults [2]. The global prevalence and mortality related to COPD is expected to increase in coming years owing to an increase in the number of cigarette smokers. In fact, COPD is projected to emerge as the third leading cause of death by $2020[3,4]$. Globally, there has been a gradual increase in the concerns related to healthcare for COPD, especially for comorbidities related to it.

In 2010, the global prevalence of osteoporotic fracture in patients aged 50 years or more was recorded to be 158 million. These incidences of osteoporotic fracture are expected to double by 2040 [5]. Osteoporotic fractures are associated with significant healthcare costs as they have been shown to adversely affect the overall quality of life [5]. Thus, patients with COPD and osteoporotic fractures account for significant healthcare expenditures for the sexes, making them a major global public health challenge $[6,7]$.

Several previous studies have reported an association between the use of steroids and risk of new-onset osteoporotic fractures (NOFs) in patients with COPD $[8,9]$. In particular, an increased risk of NOF was observed, especially in case of chronic steroid user, suggesting a direct osteoporotic effect of steroids [10, 11]. This association of steroids with osteoporosis and osteoporotic fractures might be contributed by promotion of apoptosis of both osteoblasts and osteoclasts and decrease in their recruitment from progenitor cells [11]. In comparison to this, statins might influence bone metabolism by increasing the formation of bones and decreasing the risk of NOF [12]. Recently, several prospective and retrospective studies have investigated the association between COPD and NOF in statin-treated patients [13-15]. However, the outcome of these studies was limited by small sample size and insufficient follow-up periods $[16,17]$. Notably, the association between COPD or its prescribed drugs and a higher risk of NOF in statin-treated patients with dyslipidemia over a long-term follow-up remains unclear. The present study aimed to investigate the association between COPD and NOF in statin-treated patients in Taiwan, over a period of 10 years.

\section{Methods}

\section{Study designs and cohort populations}

A population-based case-control study was conducted and used data obtained from claim forms submitted to the Taiwan National Health Insurance Research Database
(NHIRD) between 2004 and 2013. The National Health Insurance program was established in 1995 in Taiwan and currently has a coverage rate of $99 \%$.

The Longitudinal Health Insurance Research Database (LHIRD) 2010 was used in this study and comprised a systematic and random sampling of the NHIRD for one million beneficiaries. Patients were included in the study if they had COPD [International Classification of Diseases, Ninth Revision, Clinical Modification, (ICD-9CM) code 491)] and used statins without osteoporotic fracture at baseline (January to March, 2004). We summarized the claim records of each patient into one record. Participants were defined as having new-onset osteoporotic fracture (ICD-9-CM codes 733.11 and 805829) or osteoporosis (ICD-9-CM code 733.11) with fracture-related surgery (ICD-9-CM codes 78.1, 78.4, 78.5, 78.9, 79, and 81) and COPD between January 01, 2004 and December 31, 2013. Patient were excluded as follows: (1) age < 40 years at baseline; (2) had a prior history of osteoporotic fracture (ICD-9-CM codes 733.11 and 805-829) or osteoporosis (ICD-9-CM code 733.11) with fracture-related surgery (ICD-9-CM codes 78.1, $78.4,78.5,78.9,79$, and 81 ) before January 01, 2004; (3) were taking calcium supplements, bisphosphonates, raloxifene, teriparatide, or calcitonin between 2004 and 2013; (4) had pathological fractures (ICD-9-CM codes 805-829) resulting from cancer metastasis (ICD-9-CM codes 140-239), renal osteodystrophy (ICD-9-CM codes 588.0), or secondary hyperparathyroidism (ICD-9-CM codes 588.81) at baseline; and (5) were experiencing other major medical problems that would leave the patient with a life expectancy of $<6$ months (die between January 2004 and July 2004). The NOF was defined as the first time that an osteoporotic fracture or osteoporosis with fracture-related surgery code appeared in the claim record. The main outcome was NOF diagnosis after the baseline date. Both cases and controls were matched 1: 1 for sex, age (5-year intervals), index date, and Charlson Comorbidity Index score.

\section{Statistical analyses}

Data are presented as valid percentages and mean values with standard deviations. Chi-square tests and $t$-tests were used for univariate analyses. Cox proportional hazards regression models were applied to calculate hazard ratio (HR) and 95\% confidence interval (CI) for the association between osteoporotic fracture and statin use in patients with COPD. Additional adjusted multiple Cox proportional hazards regression models, including sex, age, comorbidity, and concurrent medications, were implemented. Finally, the NOF-free survival rates between COPD patients in the statin-treated group and without statin-treated group were estimated by the KaplanMeier method using the log rank test. A $P<0.05$ was 
considered statistically significant. All statistical calculations were performed with Statistical Analysis software, version 9.3 (SAS Institute, Inc., Cary, NC, USA).

\section{Results}

\section{Patients' baseline characteristics}

Between 2004 and 2005, 90,646 patients with COPD were identified from the National Health Insurance Research Database $(n=1,000,000)$. Among these, 3945 patients were excluded based on the diagnosis of osteoporotic fracture before January 01, 2004; 480 patients were lost to follow-up, and 33 patients died. A total of 86,188 patients with COPD and statin user were selected for this study. Another 86,188 patients with COPD and statin non-user, who were assigned to nonuser group after 1: 1 sex-matched, age-matched, index date-matched, and Charlson Comorbidity Index scorematched randomly selected participants (Fig. 1). Baseline characteristics, comorbidities, and concurrent medication use between the statin user group and statin nonuser groups in patients with COPD are presented in Table 1 . The mean ages of patients with and without statin-treated were 64.4 and 64.5 years, respectively. Study participants were predominantly women (54.4\%).

Hypertension and diabetes mellitus were the most commonly observed comorbidities. Except for congestive heart failure, dementia, cancer, depression, and alcoholism, all other comorbidities, such as hypertension, coronary artery disease, chronic kidney disease, diabetes mellitus, hyperthyroidism, rheumatoid arthritis, and obesity, were significantly different between the statin user group and the statin non-user group $(P<0.05)$. The distribution of prescriptions, including loop or thiazide diuretics, nondihydropyridine calcium channel blockers, alpha-blockers, ACE inhibitors, selective serotonin reuptake inhibitors, glucocorticoids, and hormone replacement therapy, was also significantly different between NOF group and the non-NOF group $(P<0.05$; Table 1$)$.

\section{Relative risk of NOF in COPD patients with statin use}

Initially, the crude OR of NOFs was higher among patients with COPD in the statin-treated group (HR, 1.12; 95\% CI, 1.01-1.25) than that among patients with COPD in the without statin-treated group. However, the risk

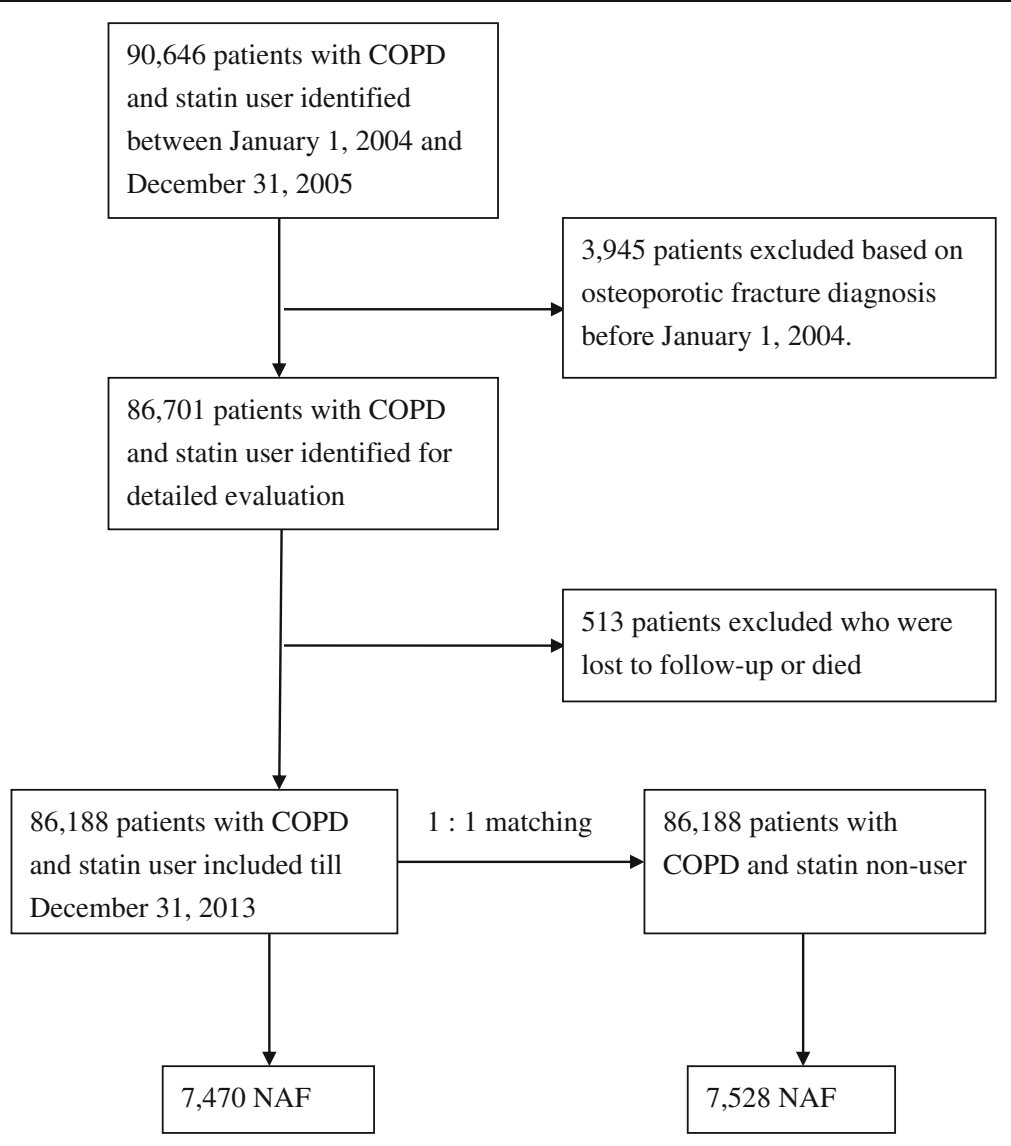

NOF: New-onset osteoporotic fracture.

Fig. 1 Flowchart of selection of patients for the inclusion in this study 
Table 1 Baseline characteristics of all patients

\begin{tabular}{|c|c|c|c|}
\hline & Statin user $(N=86,188)$ & Statin non-user $(N=86,188)$ & $P$ value \\
\hline Age (year-old) & $64.4 \pm 12.9$ & $64.5 \pm 13.1$ & 0.998 \\
\hline Sex & & & 1.000 \\
\hline Male (\%) & $39,302(45.6)$ & $39,302(45.6)$ & \\
\hline Female (\%) & $46,886(54.4)$ & $46,886(54.4)$ & \\
\hline Index date (years) & 4.5 & 4.5 & 1.000 \\
\hline Charlson score (Mean \pm SD) & $4.1 \pm 1.0$ & $3.8 \pm 0.9$ & 0.902 \\
\hline \multicolumn{4}{|l|}{ Comorbidities (n, \%) } \\
\hline Hypertension (\%) & $19,909(23.1)$ & $10,170(11.8)$ & $<0.001$ \\
\hline CAD (\%) & $3706(4.3)$ & $1724(2.0)$ & $<0.001$ \\
\hline $\mathrm{CHF}(\%)$ & $371(0.4)$ & $259(0.3)$ & 0.663 \\
\hline CKD (\%) & $3017(3.5)$ & $1034(1.2)$ & $<0.001$ \\
\hline DM (\%) & $6206(7.2)$ & $2758(3.2)$ & $<0.001$ \\
\hline Dementia (\%) & $172(0.2)$ & $431(0.5)$ & 0.526 \\
\hline Cancer (\%) & $1724(2.0)$ & $2591(3.0)$ & 0.450 \\
\hline Hyperthyroidism (\%) & $172(0.2)$ & $1120(1.3)$ & 0.011 \\
\hline Obesity (\%) & $259(0.3)$ & $2155(2.5)$ & 0.005 \\
\hline Depression (\%) & $1034(1.2)$ & $948(1.1)$ & 0.978 \\
\hline Rheumatoid arthritis & $690(0.8)$ & $690(0.8)$ & 1.000 \\
\hline Alcoholism (\%) & $171(0.2)$ & $431(0.5)$ & 0.669 \\
\hline \multicolumn{4}{|l|}{ Concurrent medications (n) } \\
\hline Loop diuretics (\%) & $9912(11.5)$ & $5171(6.0)$ & $<0.001$ \\
\hline Thiazide diuretics (\%) & $4482(5.2)$ & $2155(2.5)$ & $<0.001$ \\
\hline Beta-blockers (\%) & $5731(6.5)$ & $5688(6.6)$ & 0.870 \\
\hline DHP CCBs (\%) & $10,429(12.1)$ & $9308(10.8)$ & 0.661 \\
\hline Non-DHP CCBs (\%) & $3275(3.8)$ & $1551(1.8)$ & $<0.001$ \\
\hline Alph-blockers (\%) & $1551(1.8)$ & $517(0.6)$ & $<0.001$ \\
\hline ACE inhibitors (\%) & $3189(3.7)$ & $3792(4.4)$ & 0.047 \\
\hline ARBs (\%) & $8274(9.6)$ & $8188(9.5)$ & 0.916 \\
\hline Benzodiazepines (\%) & $25,253(29.3)$ & $24,908(28.9)$ & 0.330 \\
\hline SSRI (\%) & $862(1.0)$ & $30(0.0)$ & $<0.001$ \\
\hline Glucocorticoids (\%) & $29,304(34.0)$ & $24,564(28.5)$ & $<0.001$ \\
\hline Opioid analgesics (\%) & $5430(6.3)$ & $5688(6.6)$ & 0.222 \\
\hline HRT (\%) & $603(0.7)$ & $1207(1.4)$ & $<0.001$ \\
\hline
\end{tabular}

NOF New-onset osteoporotic fracture, CAD Coronary artery disease, CHF Congestive heart failure, CKD Chronic kidney disease, DM Diabetes millitus, DHP CCBS Dihydropyridine calcium channel blockers, ACE Angiotensin converting enzyme, ARBs Angiotensin receptor blockers, SSRI Selective serotonin reuptake inhibitors, HRT Hormone replacement therapy, SD Standard deviation

$p$ value between NOF in statin-treated group and non-NOF without statin-treated group

for NOFs was not associated with COPD after adjusting for age, sex, other comorbidities, and concurrent medications (adjusted OR, 0.81; 95\% CI, 0.55-1.21; Table 2). Finally, the Kaplan-Meier survival analysis revealed no difference in the probabilities of free from NOFs between patients with COPD with statin user and those with COPD in the without statin-treated group $(P=$ 0.354; Fig. 2).

\section{Discussion}

The results of the present study revealed that statin use was not independently associated with an increased risk of NOF in patients with COPD. Statin use might provide some beneficial effects on NOF in statin-treated patients with COPD.

A significantly higher prevalence of osteoporotic fractures has been previously reported in patients with 
Table 2 Incidence of hazard ratios (HRs) with 95\% confidence intervals (Cls) for new-onset osteoporotic fracture in statin-treated patient COPD compared with statin non-user COPD subjects

\begin{tabular}{|c|c|c|c|c|c|c|}
\hline & Crude $\beta(95 \% \mathrm{Cl})$ & Crude HR $(95 \% \mathrm{Cl})$ & $P$ value & $\begin{array}{l}\text { Adjusted } \\
\beta^{\mathrm{a}}(95 \% \mathrm{Cl})\end{array}$ & Adjusted $\mathrm{HR}^{\mathrm{a}}(95 \% \mathrm{Cl})$ & $P$ value \\
\hline COPD without statin-treated & ref & ref & & ref & ref & \\
\hline COPD in statin-treated & 0.113 (0.010 to 0.223$)$ & $1.12(1.01-1.25)$ & 0.032 & -0.211 ( -0.598 to 0.191$)$ & $0.81(0.55-1.21)$ & 0.584 \\
\hline
\end{tabular}

a $(\beta$ and HR) were adjusted for age, sex, hypertension, CAD, CHF, CKD, DM, dementia, cancer, hyperthyroidism, obesity, depression, rheumatic arthritis, alcoholism and concurrent medication

COPD as compared to healthy subjects, particularly in females [18-20]. The presence of an association between COPD and NOF has been previously reported in many studies. A cross-sectional study conducted by Watanabe et al. reported a higher prevalence (79.4\%) of osteoporotic vertebral fracture in Japanese men with COPD [18]. In a similar study, Reyes et al. reported an independent association between COPD and an increased risk of hip NOF in Catalonians [19]. However, none of the aforementioned studies involved a prospective study design. Dam and co-workers conducted a prospective study to investigate the association between COPD or asthma and NOF [14]. The results of the study revealed that male patients with COPD or asthma were associated with 42 and $164 \%$ higher risk of sustaining non-vertebral and vertebral NOF, respectively. In contrast to this, the results of the present study demonstrated absence of a significant association between risk of NOF and COPD in statin-treated patients. These differences in the results of the present study as compared to the previous studies might be attributed to differences in the baseline characteristics of the patients (one study included general population, whereas three studies included only men), study design (one study involved a prospective design, while three studies included a retrospective design), and statin use [14, 18-20].

In the present study, the association between COPD and NOF in statin-treated patients could be attributed to the shared risks associated with other conditions, such as smoking, physical inactivity, uncontrolled inflammation, and dyslipidemia [14, 20]. An independent association between statin use and lower risk of NOF has been previously demonstrated [21-23]. Statins are one of the most effective agents used in the control of dyslipidemia and prevention of cardiovascular diseases [24, 25]. In addition to this, statins might influence bone metabolism by increasing bone formation [12]. In the present study, all the patients with dyslipidemia and COPD received statin therapy, which might have incurred a beneficial effect with regard to the risk of NOF.

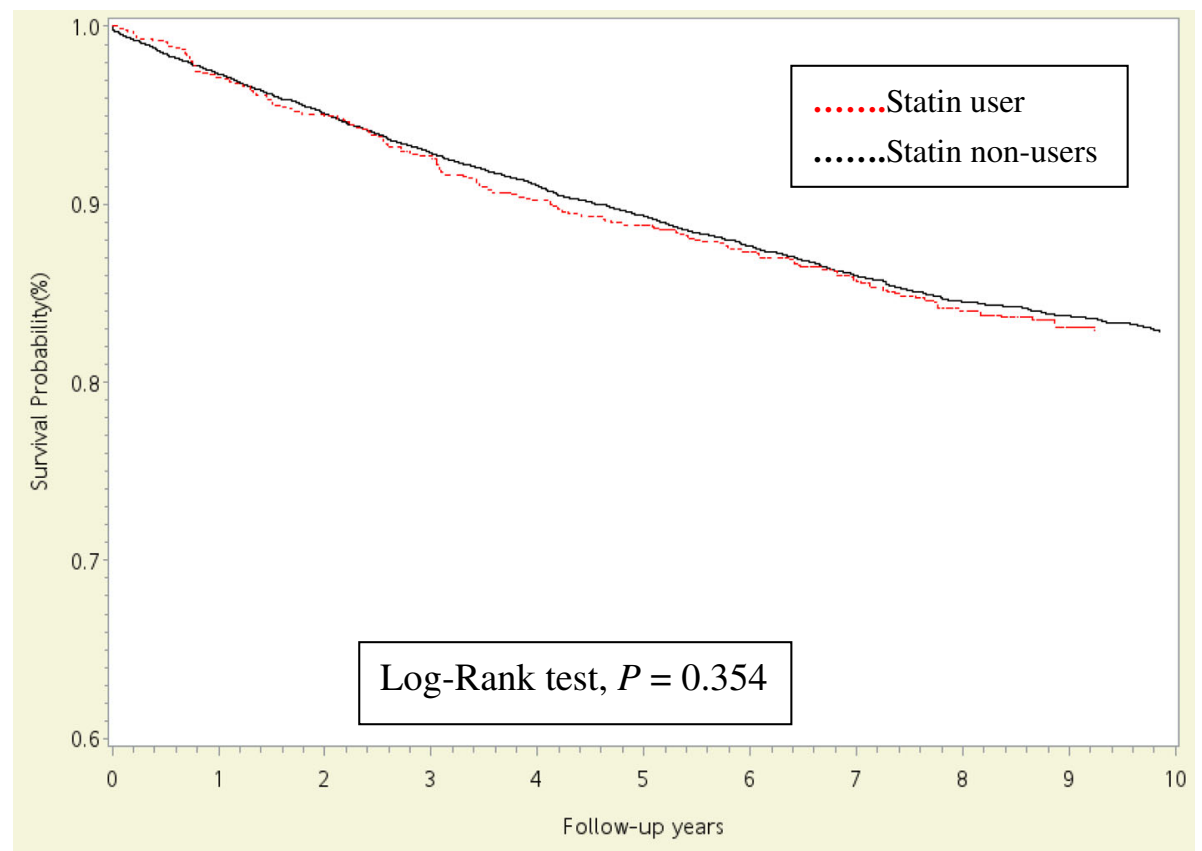

Fig. 2 Kaplan-Meier analysis comparing probabilities of free from new-onset osteoporotic fracture between COPD patients with statin-treated and without statin-treated 
In the present cohort study, COPD patients with dyslipidemia and other comorbidities, such as chronic kidney diseases, diabetes mellitus, and dementia, showed a higher risk of developing NOF as compared to the patients devoid of these comorbidities. Several previous studies, both experimental and those involving humans, have demonstrated a deteriorative effect of chronic kidney disease, diabetes mellitus, and dementia on bone metabolism [26-30]. In a similar study conducted by Reyes et al., the conditions of chronic kidney disease, diabetes mellitus, or dementia were found to be independently associated with a higher risk of hip fracture in older men [19].

The association between COPD and higher risk of NOF has been reported in several previous studies $[8,9]$. An increased risk of NOF has been observed in COPD subjects, especially in elderly patients receiving steroid therapy, suggestive of a potential direct osteoporotic effect $[10,11]$. In the present study, all the patients with dyslipidemia and COPD received statin therapy, which might have incurred a beneficial effect on the risk of NOF. Therefore, the present study proposes to include statins as an integral part of the prevention strategy for osteoporotic fractures in patients with COPD in clinical practice, and it should not be restricted only to the treatment of COPD and dyslipidemia.

\section{Study strengths and limitations}

This study has two strengths. First, this is the first evidence regarding the neutral association between statin use and NOFs in patients with COPD during a 10-year follow-up. Second, this is a population-based cohort study. Some limitations of this study need to be emphasized. First, all cases in this study were collected from claim forms of the NHIRD, and the diagnoses were based on physician reports only. Therefore, it is unclear how our findings can be generalized to patients in different regions of the world. Second, this was a descriptive, retrospective study conducted in Taiwan for over 10 years. Moreover, we excluded irregularly treated COPD patients from the analyses. Therefore, caution must be exercised in interpreting the results of this study. Third, the risk factors for osteoporotic fractures, such as obesity, body mass index, smoking status, alcohol consumption, physical activity, family history, as well as the degree and duration of the disease were not available from these secondary data. Fourth, we determined that the exposure to statins in the cohort is real, given that the claims data include medication prescriptions. However, laboratory data, treatment adherence, lifestyle adjustments and modifications, history of treated liver disease, history of resolved vitamin D deficiency, improved quality of life, increased physical activity, reduced stress, treated gastrointestinal tract disorders, and other health-related factors were not available from these secondary data. However, because the data we used were population-based data, we assumed that there were no differences among the two groups.

\section{Conclusions}

In conclusion, the results of the present study indicated that statin therapy in COPD patients was not independently associated with an increased risk of NOF. Further, these findings might support the hypothesis stating the potent pleiotropic effects of statins. In fact, the use of these drugs might prove beneficial for patients with COPD in clinical practice.

\section{Abbreviations}

ACE: Angiotensin-converting enzyme; Cl: Confidence interval; COPD: Chronic obstructive pulmonary disease; ICD-9-CM: International Classification of Diseases, Ninth Revision, Clinical Modification; HR: hazards ratio; LHIR D: Longitudinal Health Insurance Research Database; NHIRD: National Health Insurance Research Database; NOF: New-onset osteoporotic fracture.

\section{Acknowledgements}

This study was supported in parts by grants (AFTYGH-10837) from the Taoyuan Armed Forces General Hospital.

\section{Authors' contributions \\ HYC, TKL and GPJ conceived the research question and designed the study. HYC, PYS and TKL conducted statistical analysis, interpreted the results and wrote the first and subsequent drafts of the manuscript. HYC, TKL and GPJ contributed to data interpretation and revisions of the manuscript. All} authors were approved the final manuscript.

\section{Funding}

This study was supported in parts by grants (AFTYGH-10837) from the Taoyuan Armed Forces General Hospital.

\section{Availability of data and materials}

The raw data supporting the conclusions of this manuscript will be made available by the authors. The data of this study including figures and tables will be available by contacting corresponding author. The data can be used permanently after the article is published.

\section{Ethics approval and consent to participate}

This study was approved by the ethics committee of the China Medical University Hospital (DMR101-IRB2-194). Written consent was not obtained from the study participants as only de-identified data were obtained from the LHIRD 2010, and a waiver of patient consent was provided by the ethics committee for this study.

\section{Consent for publication \\ Not applicable.}

\section{Competing interests}

The authors have declared that no competing interest exists.

\section{Author details}

'Department of Pharmacy, China Medical University, Taichung, Taiwan, Republic of China. ${ }^{2}$ Department of Pharmacy, China Medical University Beigang Hospital, Yunlin County, Taiwan, Republic of China. ${ }^{3}$ Department of Pharmacy, Wan Fang Hospital, Taipei Medical University, Taipei, Taiwan, Republic of China. ${ }^{4}$ Department of Pharmacy, Taoyuan Armed Forces General Hospital, Taoyuan, Taiwan, Republic of China. ${ }^{5}$ School of Pharmacy, National Defense Medical Center, Taipei, Taiwan, Republic of China. ${ }^{6}$ Department of Internal Medicine, Chung Shan Medical University Hospital and Chung Shan Medical University, Taichung, Taiwan, Republic of China. 
Received: 2 September 2020 Accepted: 26 October 2020

Published online: 03 November 2020

\section{References}

1. Lopez AD, Shibuya K, Rao C, Mathers CD, Hansell AL, Held LS, et al. Chronic obstructive pulmonary disease: current burden and future projections. Eur Respir J. 2006:27:397-412.

2. Naghavi M, Abajobir AA, Abbafati C, Abbas KM, Abd-Allah F, Abera SF, et al. Global, regional, and national age-sex specific mortality for 264 causes of death, 1980-2016: a systematic analysis for the Global Burden of Disease Study. Lancet. 2017:390:1151-210.

3. Murray CJ, Lopez AD. Alternative projections of mortality and disability by cause 1990-2020: global burden of disease study. Lancet. 1997:349:1498-504.

4. Laniado-Laborin R. Smoking and chronic obstructive pulmonary disease (COPD). Parallel epidemics of the 21st century. Int J Environ Res Public Health. 2009;6:209-24

5. Odén A, McCloskey EV, Kanis JA, Harvey NC, Johansson H. Burden of high fracture probability worldwide: secular increases 2010-2040. Osteoporos Int. 2015;26:2243-8.

6. Lehouck A, Boonen S, Decramer M, Janssens W. COPD, bone metabolism, and osteoporosis. Chest. 2011;139:648-57.

7. Khakban A, Sin DD, FitzGerald JM, Ng R, Zafarí Z, McManus B, et al. Ten-year trends in direct costs of COPD: a population-based study. Chest. 2015;148:640-6.

8. Angeli A, Guglielmi G, Dovio A, Capelli G, de Feo D, Giannini S, et al. High prevalence of asymptomatic vertebral fractures in postmenopausal women receiving chronic glucocorticoid therapy: a cross-sectional outpatient study. Bone. 2006;39:253-9.

9. Donnan PT, Libby G, Boyter AC, Thompson P. The population risk of fractures attributable to oral corticosteroids. Pharmacoepidemiol Drug Saf. 2005;14:177-86.

10. Jehle PM. Steroid-induced osteoporosis: how can it be avoided? Nephro Dial Transplant. 2003;18:861-4.

11. Van Staa TP, Leyfkens HGM, Abenhaim L, Zhang B, Cooper C. Use of ora corticosteroids and risk of fractures. J Bone Miner Res. 2000;15:993-1000.

12. Shi MM, Kong $Y$, Song $Y$, Sun $Y Q$, Wang $Y$, Zhang $X U$, et al. Atorvastatin enhances endothelial cell function in posttransplant poor graft function. Blood. 2016:128:2988-99.

13. Chen SJ, Liao WC, Huang KH, Lin CL, Tsai WC, Kung PT, et al. Chronic obstructive pulmonary disease and allied conditions is a strong independent risk factor for osteoporosis and pathologic fracture: a population-based cohort study. QJM. 2015:108:633-40.

14. Dam TT, Harrison S, Fink HA, Ramsdell J, Barette-Conner E. Osteoporotic fractures in men research group. Bone mineral density and fractures in older men with chronic obstructive pulmonary disease or asthma. Osteoporos Int. 2010;21:1341-9.

15. Inoue D, Watanabe R, Okazaki R. COPD and osteoporosis: links, risks, and treatment challenges. Int J Chro Obstruct Pulmon Dis. 2016;11:637-48.

16. Li H, Yang DL, Ma L, Wang H, Ding WY, Yang SD. Risk factors associated with adjacent vertebral compression fracture following percutaneous vertebroplasty after menopause: a retrospective study. Med Sci Monit. 2017; 23:5271-6.

17. Ogura-Tomomatsu H, Asano K, Tomomatsu K, Miyata J, Ohmori N, Kodama $\mathrm{M}$, et al. Predictors of osteoporosis and vertebral fractures in patients presenting with moderate-to-severe chronic obstructive lung disease. COPD. 2012;9:332-7.

18. Watanabe R, Tanaka T, Aita K, Hagiya M, Homma T, Yokosuka K, et al. Osteoporosis is highly prevalent in Japanese males with chronic obstructive pulmonary disease and is associated with deteriorated pulmonary function. J Bone Miner Metab. 2015;33:392-400.

19. Reyes $C$, Estrada P, Nogués X, Orozco P, Cooper C, Díez-Pérez A, et al. The impact of common co-morbidities (as measured using the Charlson index) on hip fracture risk in elderly men: a population-based cohort study. Osteoporos Int. 2014:25:1751-8.

20. Lee PH, Kok VC, Chou PL, Ku MC, Chen YC, Horng JT. Risk and clinical predictors of osteoporotic fracture in east Asian patients with chronic obstructive pulmonary disease: a population-based cohort study. Peer J. 2016:4:e2634.

21. Lee DS, Markwardt S, Goeres L, Lee CG, Eckstrom E, Williams C, et al. Statins and physical activity in older men: the osteoporotic fractures in men study. JAMA Intern Med. 2014;174:1263-70.
22. Ward IM, Mortensen EM, Battafarano DF, Frei CR, Mansi I. Association of statins and risk of fractures in a military health system: a propensity scorematched analysis. Ann Pharmacother. 2014;48:1406-14.

23. Ibrahim N', Mohamed N, Shuid AN. Update on statins: hope for osteoporotic fracture healing treatment. Curr Drug Targets. 2013;14:1524-32.

24. Taylor F, Huffman MD, Macedo AF, Moore TH, Burke M, Davey Smith G, et al. Statins for the primary prevention of cardiovascular disease. Cochrane Database Syst Rev. 2013;1:CD004816.

25. Han N, Han SH, Song YK, Kim MG, Kim YS, Kim IW, et al. Statin therapy for preventing cardiovascular diseases in patients treated with tacrolimus after kidney transplantation. Ther Clin Risk Manag. 2017:13:1513-20.

26. Liao KM. Chronic obstructive pulmonary disease is a strong independent risk factor for osteoporosis and pathologic fractures: a population-based cohort study. QJM. 2016;109:69.

27. Nguyen TV, Eisman JA, Kelly PJ, Sambrook PN. Risk factors for osteoporotic fractures in elderly men. Am J Epidemiol. 1996;144:255-63.

28. Byberg L, Gedeborg R, Cars T, Sundström J, Berglund L, Kilander L, et al. Prediction of fracture risk in men: a cohort study. J Bone Miner Res. 2012;27:797-807.

29. Oei L, Zillikens MC, Dehghan A, Buitendijk GH, Castaño-Betancourt MC, Estrada $\mathrm{K}$, et al. High bone mineral density and fracture risk in type 2 diabetes as skeletal complications of inadequate glucose control: the Rotterdam study. Diabetes Care. 2013:36:1619-28.

30. Zhao Y, Shen L, Ji HF. Alzheimer's disease and risk of hip fracture: a metaanalysis study. Scientific World J. 2012;2012:872173.

\section{Publisher's Note}

Springer Nature remains neutral with regard to jurisdictional claims in published maps and institutional affiliations.

Ready to submit your research? Choose BMC and benefit from:

- fast, convenient online submission

- thorough peer review by experienced researchers in your field

- rapid publication on acceptance

- support for research data, including large and complex data types

- gold Open Access which fosters wider collaboration and increased citations

- maximum visibility for your research: over $100 \mathrm{M}$ website views per year

At BMC, research is always in progress.

Learn more biomedcentral.com/submissions 